Wright State University

CORE Scholar

Physics Faculty Publications

Physics

$9-1-2000$

\title{
Photoluminescence Measurements from the Two Polar Faces of $\mathrm{ZnO}$
}

\author{
R. E. Sherriff \\ D. C. Reynolds \\ David C. Look \\ Wright State University - Main Campus, david.look@wright.edu \\ B. Jogai \\ J. E. Hoelscher
}

See next page for additional authors

Follow this and additional works at: https://corescholar.libraries.wright.edu/physics

Part of the Physics Commons

\section{Repository Citation}

Sherriff, R. E., Reynolds, D. C., Look, D. C., Jogai, B., Hoelscher, J. E., Collins, T. C., Cantwell, G., \& Harsch, W. C. (2000). Photoluminescence Measurements from the Two Polar Faces of ZnO. Journal of Applied Physics, 88 (6), 3454-3457.

https://corescholar.libraries.wright.edu/physics/144

This Article is brought to you for free and open access by the Physics at CORE Scholar. It has been accepted for inclusion in Physics Faculty Publications by an authorized administrator of CORE Scholar. For more information, please contact library-corescholar@wright.edu. 


\section{Authors}

R. E. Sherriff, D. C. Reynolds, David C. Look, B. Jogai, J. E. Hoelscher, T. C. Collins, G. Cantwell, and W. C. Harsch 


\title{
Photoluminescence measurements from the two polar faces of $\mathrm{ZnO}$
}

\author{
R. E. Sherriff \\ Air Force Research Laboratory, Materials and Manufacturing Directorate, Wright-Patterson AFB, \\ Ohio 45433 \\ D. C. Reynolds, D. C. Look, B. Jogai, and J. E. Hoelscher \\ Semiconductor Research Center, Wright State University, Dayton, Ohio 45435 \\ T. C. Collins \\ Whitehurst Hall, Oklahoma State University, Stillwater, Oklahoma 74078 \\ G. Cantwell and W. C. Harsch \\ Eagle-Picher Industries, Inc., 200 B. J. Tunnell Boulevard, Miami, Oklahoma 74354
}

(Received 1 May 2000; accepted for publication 7 June 2000)

\begin{abstract}
The crystal structure of $\mathrm{ZnO}$ is wurtzite and the stacking sequence of atomic layers along the " c" axis is not symmetric. As a result, a $\mathrm{ZnO}$ crystal surface that is normal to the $c$ axis exposes one of two distinct polar faces, with $(000 \overline{1})$ being considered the $\mathrm{O}$ face and $(0001)$ the $\mathrm{Zn}$ face. Photoluminescence (PL) measurements on the two faces reveal a striking difference. Two transitions are observed in PL that are dominant from the $\mathrm{O}$ face and barely observed in PL from the $\mathrm{Zn}$ face. These lines are identified as phonon replicas of a particular $D^{0}, X$ transition using energy separations, excitation dependence, and time-resolved PL measurements. In addition, PL emission from free excitons is found to be more intense from the $\mathrm{O}$ face than from the $\mathrm{Zn}$ face. (C) 2000 American Institute of Physics. [S0021-8979(00)02018-1]
\end{abstract}

\section{INTRODUCTION}

The crystal structure of $\mathrm{ZnO}$ is wurtzite, and the stacking sequences of atomic layers along the " $c$ " axis are not symmetric. As a result, a $\mathrm{ZnO}$ crystal surface that is normal to the $c$ axis exposes one of two distinct polar faces, with $(000 \overline{1})$ being considered the $\mathrm{O}$ face and (0001) the $\mathrm{Zn}$ face. The two faces are known to be structurally and chemically different. ${ }^{1,2}$ They have been identified by $\mathrm{x}$-ray diffraction, low energy electron diffraction, ${ }^{3}$ photoelectron diffraction, ${ }^{4}$ coaxial impact-collision ion scattering spectroscopy, ${ }^{5}$ the sign of the piezoelectric coefficient, and etch rate measurements in $\mathrm{HCl}$ or $\mathrm{H}_{2} \mathrm{NO}$.

In the current paper we compare photoluminescence (PL) measurements on the two polar faces of $\mathrm{ZnO}$. Results from the two faces have much in common-the strongest emission comes from a set of lines associated with neutraldonor-bound excitation $\left(D^{0}, X\right)$ complexes ${ }^{7}$-but there are two major differences. The most striking difference is observed at energies below those of the $D^{0}, X$ complex lines: PL from the $\mathrm{O}$ face exhibits two lines whose PL intensity is dramatically reduced in PL from the Zn face. Energy separations, excitation dependence, and time-resolved PL measurements all suggest that these lines are phonon replicas of a particular $D^{0}, X$ transition. The other major difference appears in spectra at energies above those of the $D^{0}, X$ complexes. PL emission from free excitons is considerably more intense from the $\mathrm{O}$ face than from the $\mathrm{Zn}$ face.

\section{EXPERIMENT}

The $\mathrm{ZnO}$ sample was grown by a seeded physical vapor transport method. The $c$ axis of the crystal is normal to the growing surface. Temperature-dependent Hall effect measurements yielded a hydrogenic $(60 \mathrm{meV})$ donor concentration $N_{D}$ of $1 \times 10^{17} \mathrm{~cm}^{-3}$, and a total acceptor concentration $N_{A}$ of $2 \times 10^{15} \mathrm{~cm}^{-3}$. Time-integrated photoluminescence spectra were measured at $2 \mathrm{~K}$ with the sample immersed in liquid He. PL excitation was provided by the $3250 \AA$ line of a $\mathrm{HeCd}$ laser. The spectra were analyzed by means of a high resolution $4 \mathrm{~m}$ grating spectrometer equipped with an RCA C 31034A photomultiplier tube. Time-resolved photoluminescence measurements were made with a Hamamatsu model C1587 synchroscan streak camera. The excitation source was a frequency-tripled mode-locked Ti:sapphire laser producing pulses with a wavelength around $2750 \AA$ and a nominal pulse width below $1 \mathrm{ps}$. Although the streak camera is capable of $10 \mathrm{ps}$ resolution, trigger jitter and the narrow spectrometer bandwidth limited the effective temporal resolution to about $50 \mathrm{ps}$.

\section{RESULTS}

$\mathrm{PL}$ spectra from the $\mathrm{O}$ face of the $\mathrm{ZnO}$ sample are shown in Fig. 1(a) for various excitation intensities. The strong set of lines near $3.36 \mathrm{eV}$ result from neutral-donor-bound excitation complexes $\left(D^{0}, X\right)$ associated with defect pairs. ${ }^{7}$ The peak at $3.3779 \mathrm{eV}$ is the free exciton emission. Note the strong excitation dependence of the $3.3622 \mathrm{eV}$ line compared to that of other $D^{0}, X$ lines-at the lowest exciting intensity, it is not even visible. PL spectra from the $\mathrm{Zn}$ face of the same sample are shown in Fig. 1(b). Except for a small shift in energy, the $D_{0}, X$ lines behave similarly on both faces. In contrast, the free exciton lines observed in the O-face PL are essentially absent in the $\mathrm{Zn}$-face PL. A more striking contrast in PL from the two faces is evident in Fig. 2, which 

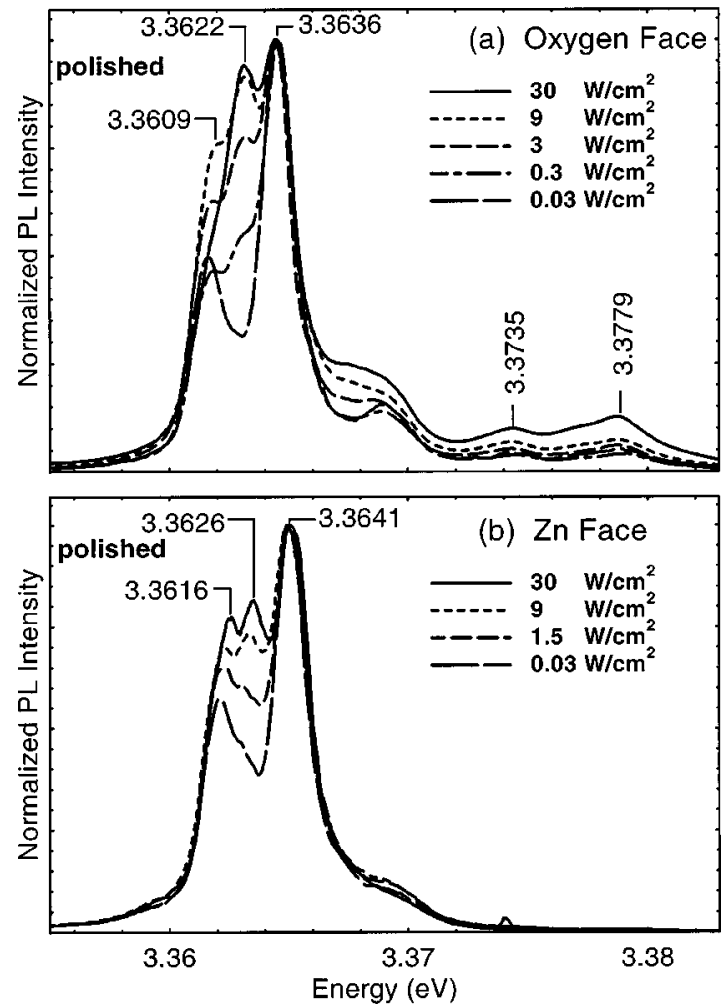

FIG. 1. Normalized $\mathrm{ZnO}$ photoluminescence spectra (above $3.35 \mathrm{eV}$ ) from (a) the $\mathrm{O}$ face and (b) the $\mathrm{Zn}$ face. Excitation intensities are given in the legends. The $\mathrm{O}$-face spectra at the two highest excitation intensities exhibited small shifts in emission energy, possibly from band-renormalization effects. These shifts were removed for improved clarity: the $30 \mathrm{~W} / \mathrm{cm}^{2}$ spectrum was shifted by $+0.59 \mathrm{meV}$, and the $9 \mathrm{~W} / \mathrm{cm}^{2}$ spectrum was shifted by $+0.25 \mathrm{meV}$.

displays spectra for energies below $3.35 \mathrm{eV}$. The spectra from the $\mathrm{O}$ face in Fig. 2(a) display lines at 3.2367 and $3.3115 \mathrm{eV}$ that are not evident in the spectra from the $\mathrm{Zn}$ face in Fig. 2(b). These lines also depend more strongly on excitation intensity than do the surrounding spectral features, reminiscent of the 3.3622 line in Fig. 1(a). To rule out the possibility that polishing damage may influence the PL differently from the two polar faces of $\mathrm{ZnO}$, the polished faces were etched in concentrated $\mathrm{Hcl}$ for $10 \mathrm{~min}$. The strong excitation dependence of the line near $3.3622 \mathrm{eV}$ for both the $\mathrm{O}$ face and the $\mathrm{Zn}$ face is still evident as shown in Figs. 3(a) and $3(\mathrm{~b})$, respectively. At the lowest exciting intensity the line is missing from both faces as was the case for the polished faces. At longer wavelengths the lines at 3.3091 and $3.2342 \mathrm{eV}$ are clearly dominant over the same energy positions on the $\mathrm{Zn}$ face as is seen in Fig. 4. This also follows the pattern observed for the polished faces. A cleaved $\mathrm{Zn}$ face was obtained and the spectral regions shown in Figs. 1(b) and 3(b) and 2(b) and 4(b) are repeated for the cleaved $\mathrm{Zn}$ face in Fig. 5. The spectral features are very similar for all three surface treatments giving evidence that the optical differences observed for the two polar faces of $\mathrm{ZnO}$ are intrinsic to the material. We were not successful in obtaining a cleaved $\mathrm{O}$ face since the preferred cleavage is parallel to the $c$ axis in $\mathrm{ZnO}$.

Since the $3.3622 \mathrm{eV}$ line results from direct recombination of a particular $D^{0}, X$ complex, we suggest that the
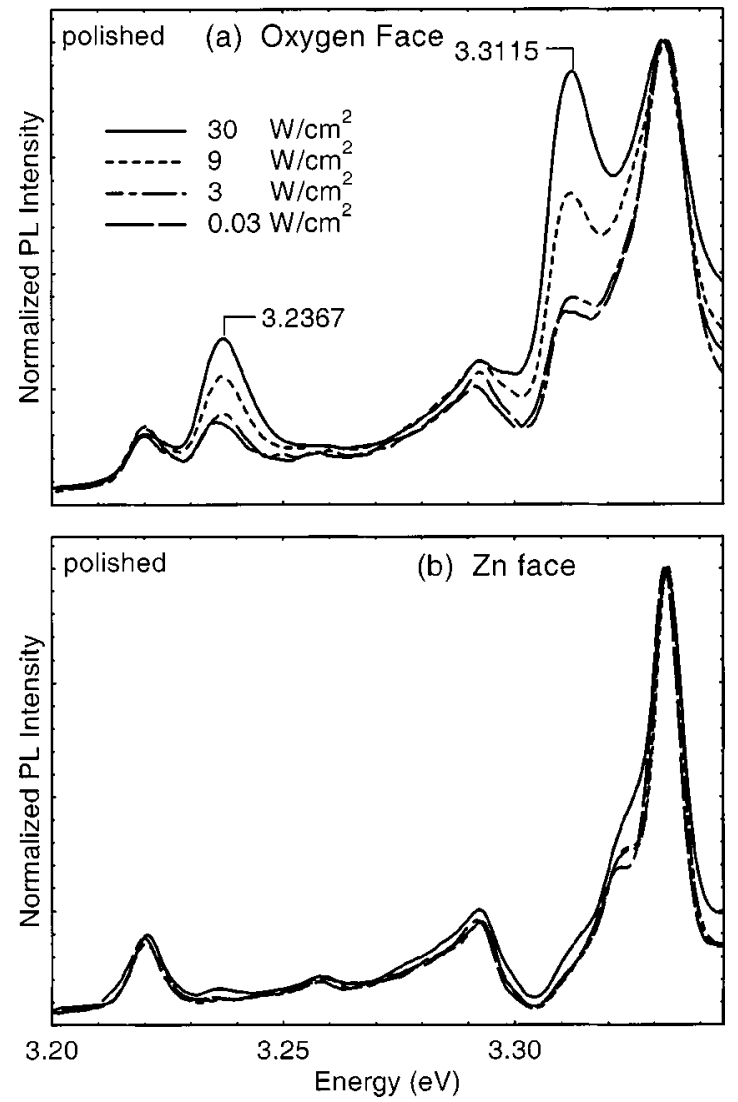

FIG. 2. Normalized $\mathrm{ZnO}$ photoluminescence spectra (below $3.35 \mathrm{eV}$ ) from (a) the $\mathrm{O}$ face and (b) the $\mathrm{Zn}$ face. The excitation intensities in the legend apply to both (a) and (b).
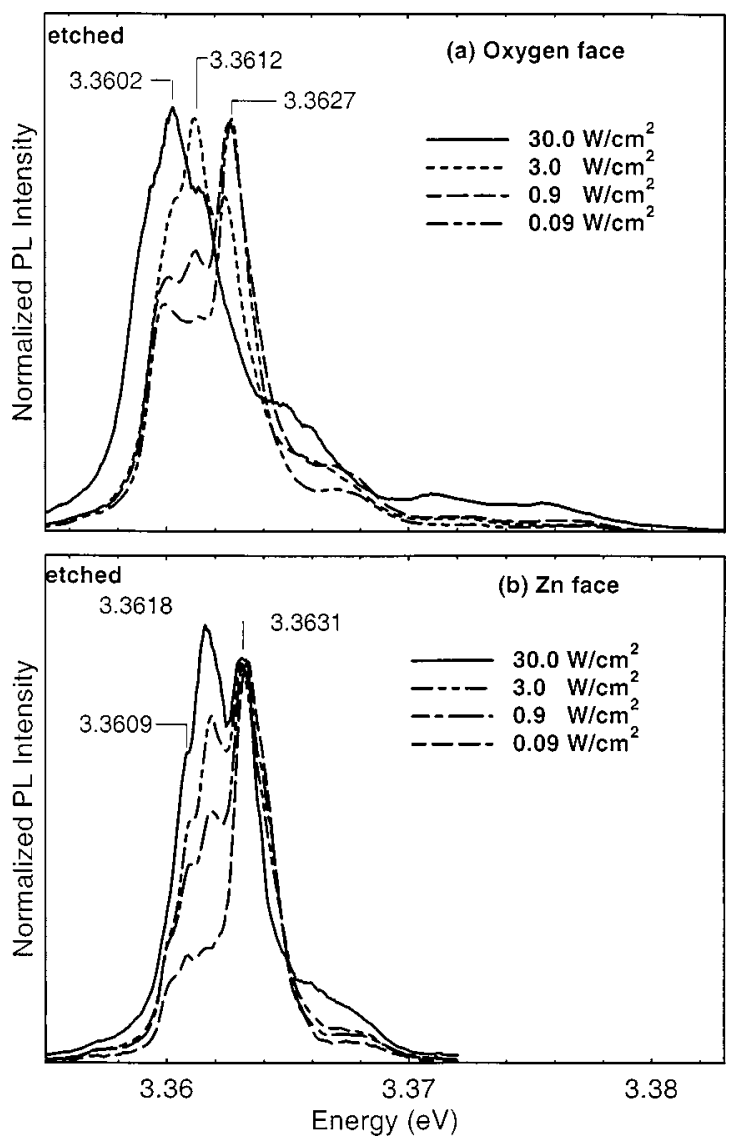

FIG. 3. Repeat of Fig. 1 for etched faces. 

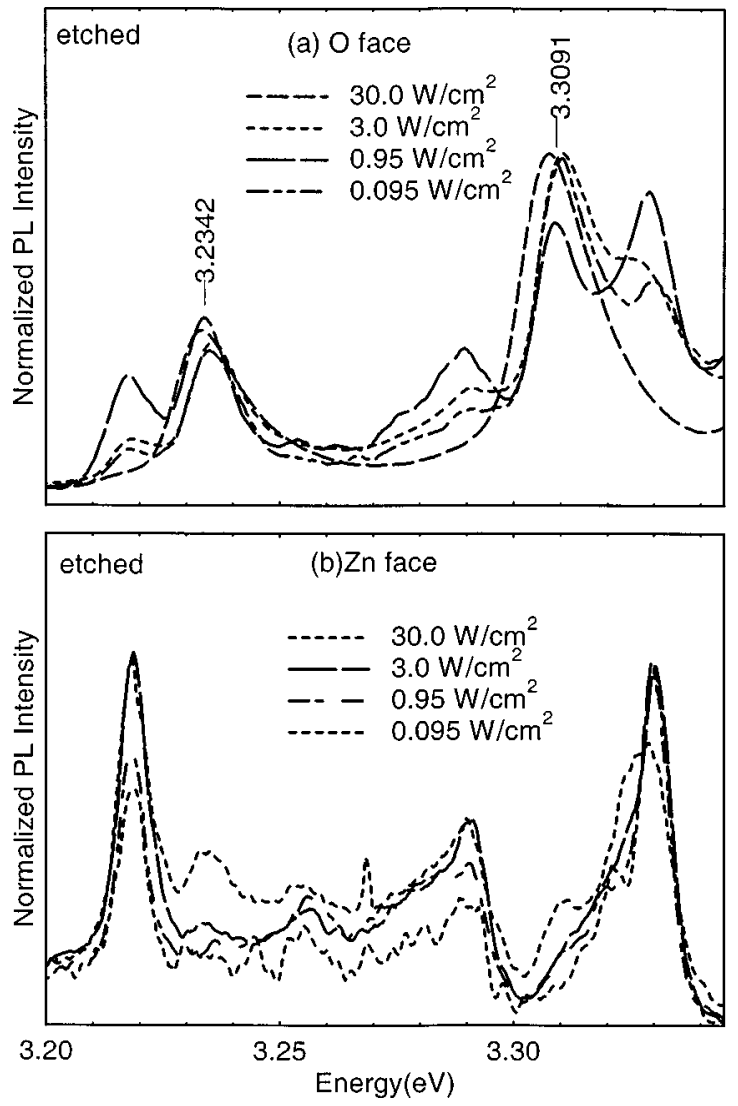

FIG. 4. Repeat of Fig. 2 for etched faces.

$3.3115 \mathrm{eV}$ line results from collapse of the same complex along with emission of an $E_{1}$-TO phonon, and the $3.2367 \mathrm{eV}$ line results from collapse of the complex with emission of both an $E_{1}-\mathrm{TO}$ phonon and an $E_{1}-\mathrm{LO}$ phonon. The observed energy separations imply energies of $50.7 \mathrm{meV}$ for the $E_{1}-\mathrm{TO}$ phonon and $74.8 \mathrm{meV}$ for the $E_{1}-\mathrm{LO}$ phonon, in close agreement with 50.5 and $72.3 \mathrm{meV}$ obtained from Raman measurements. ${ }^{8}$ Curiously, no phonon replica is observed near 3.2874 implying that the $D^{0}, X$ complex does not collapse and excite only a single $E_{1}-\mathrm{LO}$ phonon. This may suggest that the coupling between the $E_{1}-\mathrm{LO}$ phonon and the transverse exciton is weak.

Both reduced free-exciton emission and the absence of phonon replicas suggest that the local crystal environment near the $\mathrm{Zn}$ face is different from that near the $\mathrm{O}$ face. Perhaps the $\mathrm{Zn}$ face is more subject to atmospheric contamination than the $\mathrm{O}$ face. The resulting surface state defects could lead to band tailing that would absorb the near-band-edge free-exciton emission. The fact that PL from the $\mathrm{Zn}$ face clearly exhibits the parent $D^{0}, X$ transition [Fig. 1(b)] but not the phonon replicas [Fig. 2(b)] indicates that either the $D^{0}, X$ transition cannot couple to phonons near the $\mathrm{Zn}$ face, or the requisite phonons are not supported near the $\mathrm{Zn}$ face.

To further verify the identification of the phonon replicas, time-resolved PL was used to measure the decay lifetimes for the $3.3622,3.3115$, and $3.2367 \mathrm{eV}$ lines. Results are shown in Fig. 6. The data display single exponential decays for all of the transitions over several times the radiative recombination lifetime. Decay times were obtained from
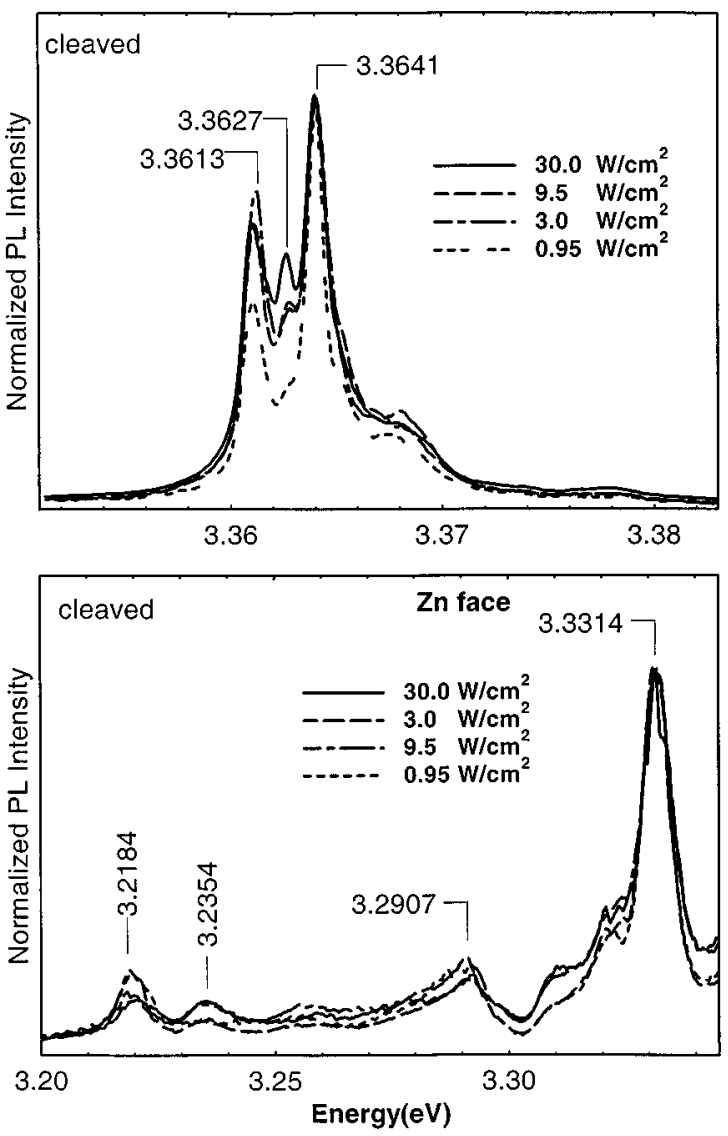

FIG. 5. Repeat of Figs. 1(b) and 3(b) and 2(b) and 4(b) for the $\mathrm{Zn}$ cleaved face.

a least-squares fit of the data to a single exponential for intensities between 0.85 and 0.05 . The decay time for the $D^{0}, X$ transition at $3.3622 \mathrm{eV}$ was $440 \mathrm{ps}$ while the decay times for the phonon replicas at 3.3115 and $3.2367 \mathrm{eV}$ were 490 and $480 \mathrm{ps}$, respectively. Since the phonon replicas presumably result from low-probability decay branches for the $D^{0}, X$ state, one would expect their intensities to track the decaying $D^{0}, X$ state population. This would make the replica decay lifetimes match the parent transition lifetime, as is observed.

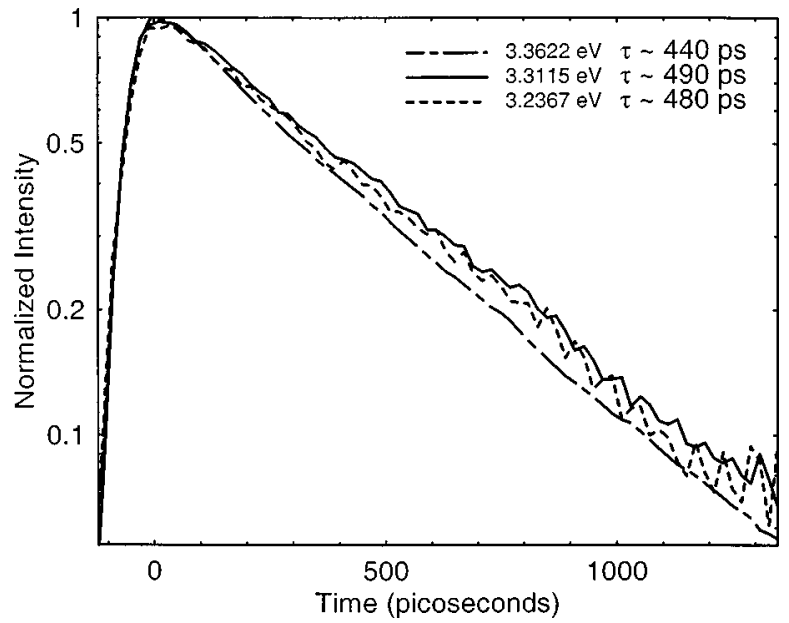

FIG. 6. Time-resolved photoluminescence intensity decays for the $D^{0}, X$ line at $3.3622 \mathrm{eV}$ and its phonon replicas at 3.3115 and $3.2367 \mathrm{eV}$. 


\section{CONCLUSION}

We have measured photoluminescence (PL) spectra from the polar faces of $\mathrm{ZnO}$. Distinct differences were observed. PL from the $\mathrm{O}$ face exhibits two transitions that are clearly dominant over transitions from the same two energy positions with respect to the Zn face. Using energy separations, excitation dependence, and time-resolved PL measurements, these lines are identified as phonon replicas of a particular $D^{0}, X$ transition. In addition, PL emission from free excitons is considerably more intense from the $\mathrm{O}$ face than from the $\mathrm{Zn}$ face. These features observed for three different surface treatments points to their intrinsic nature.

\section{ACKNOWLEDGMENTS}

The authors would like to thank C. Huang for technical support. The work of D.C.R., D.C.L., B.J., and J.E.H. was performed at Wright Patterson Air Force Base under USAF
Contract No. F33615-95-C-1619. This work was partially supported by the Air Force Office of Scientific Research (AFOSR).

${ }^{1}$ A. N. Mariano and R. E. Hanneman, J. Appl. Phys. 34, 384 (1963).

${ }^{2}$ Z. K. Tang, P. Yu, G. K. L. Wong, M. Kawasaki, A. Ohtomo, H. Koinuma, and Y. Segawa, Solid State Commun. 103, 459 (1999); Y. Segawa, A. Ohtomo, M. Kawasaki, Z. K. Tang, P. Yu, and G. K. L. Wong, Phys. Status Solidi B 202, 669 (1997).

${ }^{3}$ V. E. Henrich, H. J. Zeiger, E. I. Solomon, and R. R. Gay, Surf. Sci. 74, 682 (1978).

${ }^{4}$ M. Galeotti, A. Atrei, V. Bardi, G. Rovida, M. Torrini, E. Zaazzi, A. Santucci, and A. Klimov, Chem. Phys. Lett. 222, 349 (1994).

${ }^{5}$ T. Ohnishi, A. Ohtomo, M. Kawasaki, K. Takahashi, M. Yoshimoto, and H. Koinuma, Appl. Phys. Lett. 72, 824 (1998).

${ }^{6}$ T. Matsuoka, N. Yoshimoto, T. Sasaki, and A. Katsui, J. Electron. Mater. 21, 157 (1992).

${ }^{7}$ D. C. Reynolds, D. C. Look, B. Jogai, C. W. Litton, W. Harsch, and G. Cantwell, Phys. Rev. B 57, 12151 (1998).

${ }^{8}$ T. C. Damen, S. P. S. Porto, and B. Tell, Phys. Rev. 142, 570 (1966). 